\title{
Influence of Ammonium Polyphosphate/Lignin Ratio on Thermal and Fire Behavior of Biobased Thermoplastic: The Case of Polyamide 11
}

\author{
Aurélie Cayla $^{1}{ }^{(0)}$, François Rault ${ }^{1}\left(\mathbb{D}\right.$, Stéphane Giraud ${ }^{1, * \mathbb{C}}$, Fabien Salaün ${ }^{1}{ }^{(}$, \\ Rodolphe Sonnier ${ }^{2}$ and Loïc Dumazert ${ }^{2}$ \\ 1 ENSAIT, GEMTEX_Laboratoire de Génie et Matériaux Textiles, F-59000 Lille, France; \\ aurelie.cayla@ensait.fr (A.C.); francois.rault@ensait.fr (F.R.); fabien.salaun@ensait.fr (F.S.) \\ 2 IMT Mines d'Alès, Centre des Matériaux des Mines d'Alès-Pôle Matériaux Polymères Avancés, \\ 30100 Alès, France; rodolphe.sonnier@mines-ales.fr (R.S.); loic.dumazert@mines-ales.fr (L.D.) \\ * Correspondence: stephane.giraud@ensait.fr; Tel.: +33-320-256-464
}

Received: 17 March 2019; Accepted: 7 April 2019; Published: 8 April 2019

check for updates

\begin{abstract}
Flame retardancy of polymers is a recurring obligation for many applications. The development trend of biobased materials is no exception to this rule, and solutions of flame retardants from agro-resources give an advantage. Lignin is produced as a waste by-product from some industries, and can be used in the intumescent formation development as a source of carbon combined with an acid source. In this study, the flame retardancy of polyamide 11 (PA) is carried out by extrusion with a kraft lignin (KL) and ammonium polyphosphate (AP). The study of the optimal ratio between the $\mathrm{KL}$ and the AP makes it possible to optimize the fire properties as well as to reduce the cost and facilitates the implementation of the blend by a melting process. The properties of thermal decomposition and the fire reaction have been studied by thermogravimetric analyzes, pyrolysis combustion flow calorimetry (PCFC) and vertical flame spread tests (UL94). KL permits a charring effect delaying thermal degradation and decreases by $66 \%$ the peak of heat release rate in comparison with raw PA. The fire reaction of the ternary blends is improved even if KL-AP association does not have a synergy effect. The 25/75 and 33/67 KL/AP ratios in PA give an intumescence behavior under flame exposure.
\end{abstract}

Keywords: lignin; polyamide 11; ammonium polyphosphate; thermal decomposition; fire reaction

\section{Introduction}

Until now the plastic industry was governed by the use of petroleum resources. However, an evolution of the sector is underway. In the last few years, a transition has taken place between fully fossil-based polymers and fully-biobased polymers being replaced by partially biobased ones. Biobased polymers can be considered as macromolecular materials coming from biological resources and transformed by humans to be used in various activities in the form of massive sheets, films, or fibers. Biobased polyethylene (PE), polylactic acid (PLA), or even polyamide 11 (PA) derived from castor oil are some examples of novel thermoplastic polymers able to compete with conventional polymers. Nevertheless, in order to ensure their development and their use on the market, only emphasizing the environmental benefits for those polymers compared to those derived from petroleum resources is not enough. Indeed, these polymers must satisfy the same prerequisites as their predecessors. They have to reach the same criteria related to health, legislation, and the economy, as well as various performance criteria. The reduction of fire risks is one of the properties required and sometimes mandatory to access sectors such as transport and buildings. One of the challenges 
is then to guarantee the security of the proposed solutions while preserving as much as possible the bio-sourced aspect. Thus in recent years some of the research related to the flame retardancy of polymers has focused on the use of "green" flame retardant additives [1].

Different strategies exist and/or co-exist in order to fireproof petroleum-based polymers and can be transposed to the biobased ones. Two modes of actions, i.e., in the gas phase or condensed phase, may operate independently or together. Their mechanisms require radical inhibition or dilution of the combustion gas in the first mode, and endothermic degradation or dilution of the polymer, or even creation of a physical and/or thermal protective barrier, in the second mode. The latter approach refers mainly to the concept of intumescence and consequently to intumescent systems. An acidic source, a blowing or swelling agent, and a carbonizing agent are traditionally involved in the development of such systems that lead to the formation of an intumescent char (expanded carbonaceous barrier) upon heating. One of the most studied formulations is based on phosphorus-based additives able to release phosphoric acid, polyols as a carbon source and melamine as a blowing agent. These formulations can sometimes be limited to the use of only two components. Indeed, some components such as ammonium polyphosphate (AP) can act as an acid source and a swelling agent. Many studies have therefore been interested in developing fully (or at least partially) biobased intumescent formulations. In the case of biobased polymers, the use of natural additive is, even more so, an obvious solution to develop fire retardant formulation. It allows preservation of the original philosophy of sustainable development and the production of eco-friendly new high value-added polymers. Thus, for the first time, scientists have especially tried to substitute carbon sources traditionally used for biobased polymers. Formulations combining AP and alternative natural-based carbon sources such as starch [2-4], $\beta$-cyclodextrin [5-7], and chitosan [8] have been tested with one of the most investigated biobased polymers, i.e., PLA. Among the other natural-based compounds such as DNA, proteins, other saccharide-based compounds (sorbitol, xylitol, etc.), or derivatives from them (ex: isosorbide), biobased aromatic products, and in particular lignin, are of great interest to develop intumescent formulations. It is mentioned that its chemical structure (content of hydroxyl groups and aromatic structure) promotes the formation of a high char yield after decomposition and that its fire-retardant effect can be improved by associating other flame-retardant components [9]. Furthermore, lignin is an abundant co-product of the pulp and paper industry. Therefore, it can be considered as a waste of them and consequently provide a low-cost, eco-friendly alternative to petroleum-based carbon sources in intumescent systems for bioplastics. Its impact on the modification of the fire behavior of the polybutylene succinate [10,11], polylactic acid [2,12-17], or polyamide 11 [18-20] has been evaluated.

The flame retardancy of a biobased polymer such as PLA is relatively well documented in the literature. Different scientists have worked on this issue by considering several strategies including the use of intumescent systems that may be or not bio-sourced. In contrast, the fire-retardant enhancement of other biobased thermoplastic by using the concept of intumescence, in particular in polyamide 11, has up to now more rarely been investigated. Levchick et al. [21] studied the fire behavior of polyamide 11 with AP. One of the main conclusions is that the yield of residue formed seems not to be significantly influenced by AP. To the best of our knowledge, our research group is the first to consider the development of an intumescent flame retardant system for polyamide 11 with a double target, i.e., i) push the "green" concept as far as possible, and ii) keep the additives content compatible with further textile fiber forming process. The purpose of this article is to study the combustion behavior of polyamide 11 containing intumescent system composed of lignin and AP. Blends of PA with different kraft lignin (KL)/ AP ratio were prepared by melt extrusion. UL-94 and pyrolysis combustion flow calorimetry (PCFC) experiments evaluated the flame-retardant effectiveness of such a solution. Furthermore, the potential synergy between lignin and AP as well as their interactions with polyamide 11 were investigated. Even if the thermal behavior of the KL/AP powder mixtures is different with the KL/AP ratio, the PA blends with the same mixtures present a quite similar thermal and fire behavior without synergy compared to PA blends with only AP or KL. 


\section{Materials and Methods}

\subsection{Materials and Processing}

A biobased Polyamide 11 (PA), Rilsan®BMNO-TLD; $M \mathrm{n}=17,000 \mathrm{~g} / \mathrm{mol}$, melt flow index (MFI) $=14-20 \mathrm{~g} / 10 \mathrm{~min}$ at $235^{\circ} \mathrm{C}$, supplied from Arkema (Colombes, France), was chosen as the polymer matrix. The lignin used as charring agent is a kraft lignin (KL) purchased from Sigma Aldrich (Darmstadt, Germany). Ammonium polyphosphate (AP) with the reference Exolit AP 422 was supplied by Clariant (Muttenz, Switzerland). The both additives consist of a thin powder with an averaged particle size of $39 \mu \mathrm{m}$ and $15 \mu \mathrm{m}$ respectively. All the materials were dried at $80{ }^{\circ} \mathrm{C}$ for $24 \mathrm{~h}$ before any use.

\subsection{Blends Preparation}

The compositions of all the samples are listed in Table 1. In order to understand the influence of coupled additives on PA, the thermal decomposition of simple powder mixtures of both additives was assessed. Blends with PA were prepared with a suitable quantity of polymer and additives (lignin and/or ammonium polyphosphate). In order to obtain homogeneous pellets, each premix was extruded in a co-rotating, intermeshing twin screw extruder Thermo Haake (diameter of screw $=16 \mathrm{~mm}, \mathrm{~L} / \mathrm{D}$ ratio $=25)$ from Thermo Fisher Scientific (Waltham, MA, USA). The rotating speed was maintained at $100 \mathrm{rpm}$. The five heating zones of the extruder were set at temperatures 170, $190,200,220$, and $220^{\circ} \mathrm{C}$ respectively to keep the highest fluidity without damaging the components. The different formulations extruded (with or without fillers) were then cooled under ambient air and pelletized. The pellets obtained for each formulation were transformed in plates of $100 \times 13 \times 3$ $\mathrm{mm}^{3}$ (for UL94 tests) using a heat press from Dolouets (Soustons, France) at $220{ }^{\circ} \mathrm{C}$ under 50 bars.

Table 1. Blend formulations: kraft lignin (KL)-ammonium polyphosphate (AP) powder mix and polyamide $11(\mathrm{PA})$ composites.

\begin{tabular}{cccc}
\hline Sample & PA (wt. \%) & KL (wt. \%) & AP (wt. \%) \\
\hline $\mathrm{KL}_{25}-\mathrm{AP}_{75}$ & - & 25 & 75 \\
$\mathrm{KL}_{33}-\mathrm{AP}_{67}$ & - & 33 & 67 \\
$\mathrm{KL}_{50}-\mathrm{AP}_{50}$ & - & 50 & 50 \\
$\mathrm{PA}_{100}$ & 100 & - & - \\
$\mathrm{PA}_{80}-\mathrm{KL}_{20}$ & 80 & 20 & - \\
$\mathrm{PA}_{80}-\mathrm{AP}_{20}$ & 80 & - & 20 \\
$\mathrm{PA}_{80}-\mathrm{KL}_{05}-\mathrm{AP}_{15}$ & 80 & 5 & 15 \\
$\mathrm{PA}_{80}-\mathrm{KL}_{07}-\mathrm{AP}_{13}$ & 80 & 7 & 13 \\
$\mathrm{PA}_{80}-\mathrm{KL}_{10}-\mathrm{AP}_{10}$ & 80 & 10 & 10 \\
\hline
\end{tabular}

\subsection{Thermal Decomposition}

Thermogravimetric analyses were performed using a TA instruments thermal analyzer model number 2050 (New Castle, DE, USA) to study the thermal stability of blends. The sample of $6 \pm 1 \mathrm{mg}$ was placed in an open platinum crucible, and an empty platinum crucible was used as the reference. Dynamic runs were carried out from room temperature to 600 or $800{ }^{\circ} \mathrm{C}$, at a heating rate of $10{ }^{\circ} \mathrm{C} / \mathrm{min}$ in a $50 \mathrm{~mL} / \mathrm{min}$ flow of nitrogen. Thermogravimetric curves (TG) curves were recorded from experiments, and Derivative thermogravimetric (DTG) curves were obtained from TA universal data analysis software for all the samples. The decomposition parameters, such as the temperature at $5 \%$ and $50 \%$ weight loss $\left(T_{5 \%}\right.$ and $\left.T_{50 \%}\right)$, and residue at 600 or $800{ }^{\circ} \mathrm{C}$ were obtained from the TG curve. Furthermore, the maximum mass loss rate $\left(R_{\max }\right)$ and the corresponding temperature $\left(T_{\max }\right)$ for each main degradation step were obtained from DTG curves.

The residual mass difference curves were plotted in order to determine the increase or decrease in the thermal stability of the blends with the subsequent interaction between components. The residual mass difference curves were computed for the powder additive mixtures and composites samples, 
and correspond to the residual mass difference between the experimental and theoretical TG curves Equation (1).

$$
\Delta(M(T))=M_{\exp }(T)-M_{\text {theo }}(T)
$$

where, $\Delta(M(T))$ is a residual mass difference, $M_{\exp }(T)$ is the experimental residual mass of blends (variation with temperature $\mathrm{T}), M_{\text {theo }}(T)$ is the theoretical residual mass of the same composition computed by a linear combination between the experimental masses of each components. The residual mass difference of the blend at the temperature $T$ permits to give an indication on thermal stability of the blend regarding the whole thermal history until the temperature $\mathrm{T}$.

\subsection{Fire Reaction}

The flammability was evaluated on sample bars $\left(125 \times 12.5 \times 3 \mathrm{~mm}^{3}\right)$ by vertical flame spread tests according to IEC 60695-11-10 [22], also known as UL 94 burning flame test and used for plastic materials. This test is aimed at assessing the material capability to extinguish a flame. Materials were classified from their burning rate, time to flame out and dripping during burning.

We also employed pyrolysis combustion flow calorimetry (PCFC) (Fire Testing Technology, East Grinstead, UK). This technique was described by Lyon [23]. Sample amount of some milligrams is pyrolyzed with a heating ramp $(1 \mathrm{~K} / \mathrm{s})$ up to $750{ }^{\circ} \mathrm{C}$ under nitrogen flow. The gases released during the pyrolysis are removed in an oven at $900{ }^{\circ} \mathrm{C}$ in the presence of an $80 / 20 \mathrm{~N}_{2} / \mathrm{O}_{2}$ mixture. In these conditions, the total combustion of these gases takes place. According to Huggett's relation ( $1 \mathrm{~kg}$ of consumed $\mathrm{O}_{2}$ corresponds to $13.1 \mathrm{MJ}$ of released energy), the measurement of oxygen consumption by PCFC permits to calculate the heat release rate. Three tests were carried out on each formulation, and the results averaged. According to this analytical method, usual parameters were evaluated, i.e., the peak of heat release rate ( $\mathrm{pHRR}$ ) and its temperature, total heat release (THR), char residue and heat of complete combustion $(\Delta \mathrm{h})$ which is calculated by the division of the THR on mass loss fraction.

\section{Results and Discussion}

\subsection{Thermal Degradation}

Lignin is composed of many components having different decomposition pathways leading its thermal degradation following a complex process with consecutive reactions [24]. Thus, lignin decomposes slower over a broad temperature range from 200 to $500{ }^{\circ} \mathrm{C}$, and the DTG curve shows a wide and flat peak with a gentle slope line (Figure 1), due to the presence of various oxygen functional groups in its structure. Each group has different thermal stability, and therefore their scission occurs at different temperatures. During the thermal decomposition, the cleavages of the lignin functional groups lead to the formation of low molecular weight products until the chemical rearrangement of the backbone at a higher temperature with the formation of a significant char and the release of volatile products. Up to $200{ }^{\circ} \mathrm{C}$, lignin has an initial weight loss equal to around $5 \%$, mainly due to moisture release and volatile impurities. Above this temperature, the compound undergoes a two steps degradation process under an inert atmosphere. From 200 to $500{ }^{\circ} \mathrm{C}$, heated up by $10^{\circ} \mathrm{C} \cdot \mathrm{min}^{-1}$, lignin decomposes very slowly, since the max rate of degradation at $355^{\circ} \mathrm{C}$ is only about $0.2433 \% \cdot{ }^{\circ} \mathrm{C}^{-1}$, losing only $48 \mathrm{wt}$. \% of its initial mass below $500{ }^{\circ} \mathrm{C}$ (Table 2 ). During this main degradation step, the cleavage of the aryl-ether linkages results in the formation of aromatic hydrocarbons, phenolic, hydroxyphenolics, and guaiacyl/syringyl-type compounds according to Rodrigues et al. [25]. Thereafter, at the end of the pyrolysis phenols groups are transformed into pyrocatechols [26]. The degradation rate slightly decreases to $0.03 \% \cdot{ }^{\circ} \mathrm{C}^{-1}$ during the second step, with the formation of a residue of about $43 \mathrm{wt} . \%$ at $800{ }^{\circ} \mathrm{C}$ due to the formation of polycyclic aromatic hydrocarbons. 


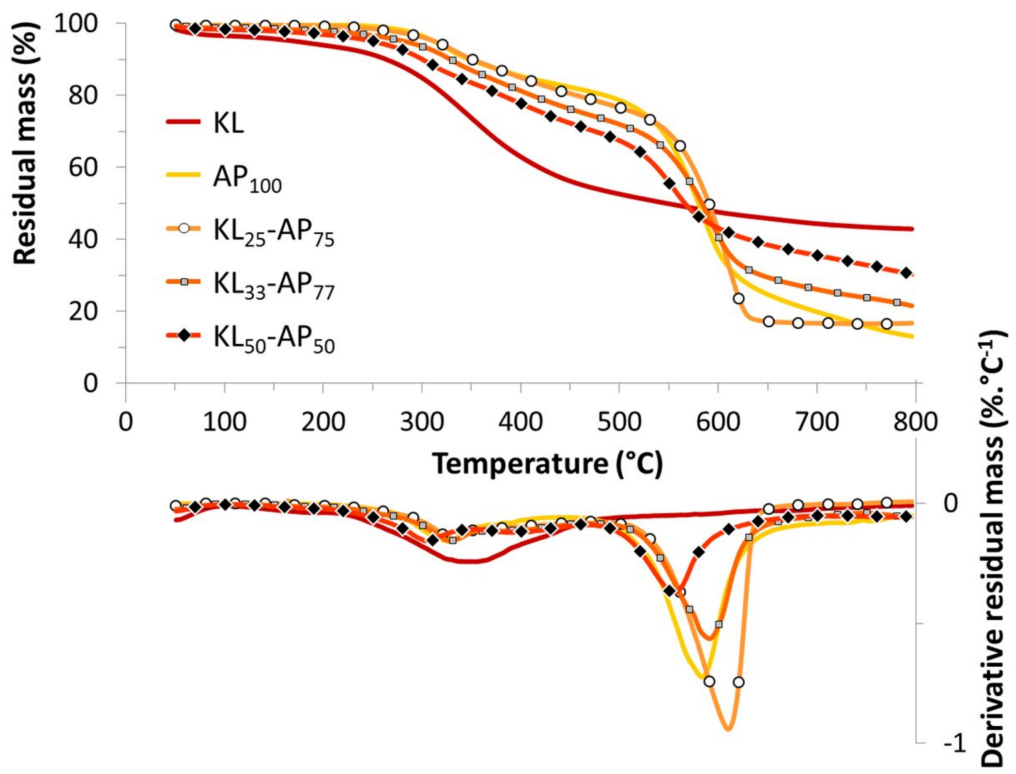

Figure 1. TG and DTG curves of KL, AP, and their blends.

Table 2. TGA results of lignin, ammonium polyphosphate and their respective blends under nitrogen atmosphere.

\begin{tabular}{|c|c|c|c|c|c|c|}
\hline \multirow{2}{*}{ Samples } & \multirow{2}{*}{$T_{5 \%}\left({ }^{\circ} \mathrm{C}\right)$} & \multirow{2}{*}{$T_{50 \%}\left({ }^{\circ} \mathrm{C}\right)$} & \multicolumn{3}{|c|}{$T_{\max }\left({ }^{\circ} \mathrm{C}\right) \& R_{\max }\left(\% \cdot{ }^{\circ} \mathrm{C}^{-1}\right)$} & \multirow{2}{*}{$\begin{array}{c}\text { Residue (\%) } \\
800{ }^{\circ} \mathrm{C} \\
\end{array}$} \\
\hline & & & Step I & Step II & Step III & \\
\hline KL & 185 & 551 & $\begin{array}{c}355 \\
0.2433\end{array}$ & - & - & 43.0 \\
\hline $\mathrm{AP}$ & 311 & 586 & $\begin{array}{c}327 \\
0.1345\end{array}$ & $\begin{array}{c}583 \\
0.7235\end{array}$ & - & 13.0 \\
\hline $\mathrm{KL}_{50}-\mathrm{AP}_{50}$ & 260 & 570 & $\begin{array}{c}305 \\
0.1571\end{array}$ & $\begin{array}{c}386 \\
0.1210\end{array}$ & $\begin{array}{c}557 \\
0.3696\end{array}$ & $33.0(28.0)$ \\
\hline $\mathrm{KL}_{33}-\mathrm{AP}_{67}$ & 280 & 578 & $\begin{array}{c}328 \\
0.1557\end{array}$ & $\begin{array}{c}593 \\
0.5613\end{array}$ & - & $23.7(23.0)$ \\
\hline $\mathrm{KL}_{25}-\mathrm{AP}_{75}$ & 314 & 590 & $\begin{array}{c}333 \\
0.1487\end{array}$ & $\begin{array}{c}611 \\
0.9401\end{array}$ & - & $16.5(20.5)$ \\
\hline
\end{tabular}

${ }^{1}$ in brackets calculated values based on additive behavior.

The thermal decomposition of ammonium polyphosphate occurs in two-steps mechanism in nitrogen conditions [27]. The first degradation step from 200 to $450{ }^{\circ} \mathrm{C}$, with $18 \%$ of weight loss, involves the water and ammonia releases as the gaseous products. Maximum degradation peak was observed at approximately $327^{\circ} \mathrm{C}$. The water elimination further induces the formation of phosphoric acid coupled to a cross-linking mechanism to lead the formation of polyphosphoric acid. The second degradation step from 450 to $700{ }^{\circ} \mathrm{C}$ is related to the dehydration and the fragmentation of polyphosphoric acid to form phosphorus oxides. In this temperature range, this material undergoes a sharp weight loss $(69 \mathrm{wt}$. \%) with the formation of a stable residue (13 wt. \%) upon heating up to $800^{\circ} \mathrm{C}$.

The presence of ammonium polyphosphate changed the thermal behavior of lignin (Figure 1 and Table 2). Regardless of the ratio, $T_{5 \%}$ and $T_{50 \%}$ were found to be increased. Compared with pure $\mathrm{KL}$, the higher initial degradation temperature is due to the higher thermal stability of $\mathrm{AP}$, while the much higher $T_{50 \%}$ (improvement of thermal stability) is mainly attributed to a much higher char residue. Furthermore, the thermal degradation occurs in two consecutive steps in the same temperature ranges than the $\mathrm{AP}$ one for the samples $\mathrm{KL}_{25}-\mathrm{AP}_{75}$ and $\mathrm{KL}_{33}-\mathrm{AP}_{67}$. According to the DTG curves, the maximal rate of weight loss for two-step degradation is at 328 and $593{ }^{\circ} \mathrm{C}, 333$ and $611^{\circ} \mathrm{C}$ 
for $\mathrm{KL}_{33}-\mathrm{AP}_{67}$ and $\mathrm{KL}_{25}-\mathrm{AP}_{75}$, respectively. The decomposition shift to a higher temperature may be attributed to the increasing content of AP. It can also be noticed the presence of an intermediate step for the sample labeled $\mathrm{KL}_{50}-\mathrm{AP}_{50}$ between 350 and $470^{\circ} \mathrm{C}$. The first step degradation of KL-AP blends occurs at a lower temperature compared to $\mathrm{KL}$, whereas the second step is shifted towards higher temperature compared to $\mathrm{AP}$, except for the sample labeled $\mathrm{KL}_{50}-\mathrm{AP}_{50}$. Above $200^{\circ} \mathrm{C}$, the mass loss rates decrease in comparison to that for KL leading to stabilization until the second degradation step. Thus, $R_{\max }$ is indeed reduced from 0.24 to $0.13 \mathrm{or} 0.15 \mathrm{wt} . \% \cdot{ }^{\circ} \mathrm{C}^{-1}$ under pyrolytic conditions. It appears that the adding of AP induces a slight thermal destabilization in the first step decomposition because phosphoric acid molecules catalyzed dehydration of lignin. For the second or third (sample for $\mathrm{KL}_{50}-\mathrm{AP}_{50}$ ) degradation step, $R_{\max }$ values are found to be lower than for AP when AP content is less than $75 \%$ in weight, and higher for this sample. At high temperature, the residue amount increases from 16.5 to 33 wt. \% as the AP content decreases.

Figure 2 allows to point out the interactions between the decomposition products of KL and AP during thermal degradation of the KL-AP mixtures. The $\mathrm{KL}_{25}-\mathrm{AP}_{75}$ and $\mathrm{KL}_{33}-\mathrm{AP}_{67}$ blends present until $600{ }^{\circ} \mathrm{C}$ a thermal stabilization phase where the residual mass of the blend is higher than the addition of the residual mass of KL and AP. This positive interaction between the decomposition products of $\mathrm{KL}$ and $\mathrm{AP}$ has two local maxima at $390{ }^{\circ} \mathrm{C}$ and $570{ }^{\circ} \mathrm{C}$. After $600{ }^{\circ} \mathrm{C}$, both blends are thermally destabilized with minima at $630{ }^{\circ} \mathrm{C}$. The positive and negative interactions are more amplified for $\mathrm{KL}_{25}-\mathrm{AP}_{75}$ (maximum $+7.5 \% /$ minimum $-13.7 \%$ ) than for $\mathrm{KL}_{33}-\mathrm{AP}_{67}$ (maximum $+3.3 \% /$ minimum $-2.2 \%$ ). The $\mathrm{KL}_{50}-\mathrm{AP}_{50}$ blend also has a maximum positive interaction $+3.5 \%$ at $390^{\circ} \mathrm{C}$, but between 530 and $600{ }^{\circ} \mathrm{C}$, the blend presents a thermal destabilization with $-4 \%$ minimum. Above $600{ }^{\circ} \mathrm{C}$, the decomposition products interact again positively with $+3.5 \%$ maximum at $710^{\circ} \mathrm{C}$. Thus, smaller AP contents lead to a higher charring effect with better thermal stabilization.

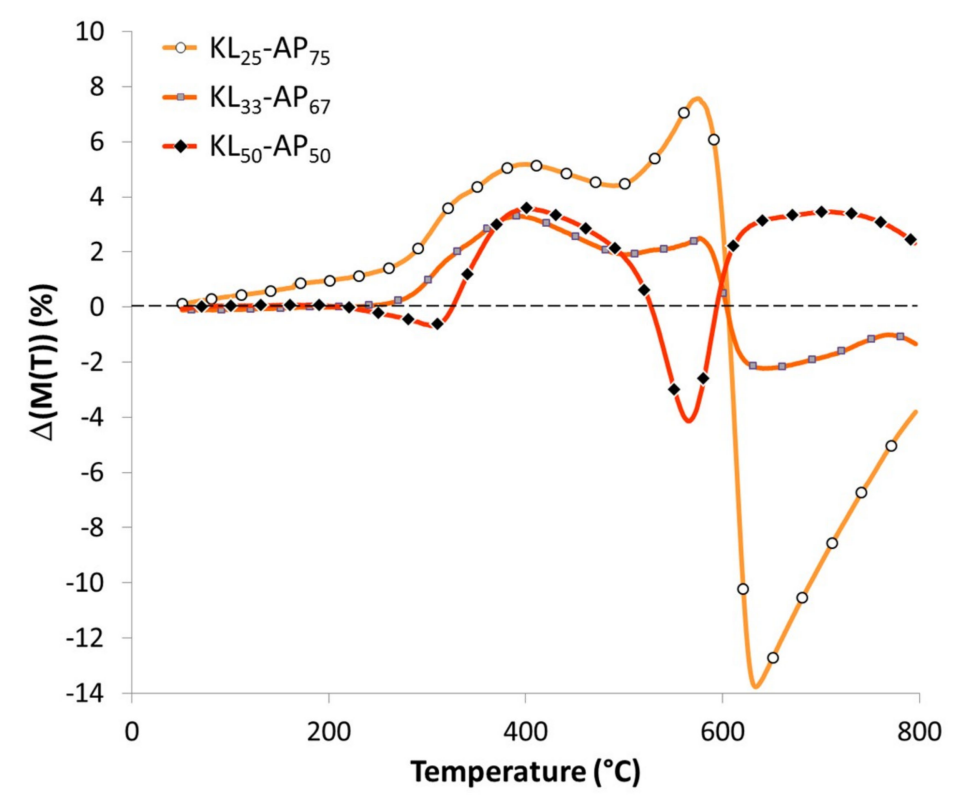

Figure 2. Curves of residual mass loss difference for KL-AP powder blends.

TG and DTG curves of PA and PA/lignin and/or ammonium polyphosphate blends under $\mathrm{N}_{2}$ atmosphere are shown in Figure 3. It can be observed that the neat PA shows a two-step thermal degradation in the range of $350-500^{\circ} \mathrm{C}$ with no char residue left at $600^{\circ} \mathrm{C}$. The primary step is located around $430{ }^{\circ} \mathrm{C}$, whereas the second and minor step occurs over $450{ }^{\circ} \mathrm{C}$ due to the decomposition of cross-linked structures obtained during heating, as a shoulder in the DTG curve suggests [21]. For PA with $20 \%$ of AP, the onset temperature and the temperature at the maximum rate of weight loss (Table 3) are shifted toward low temperature by respectively 30 and $40{ }^{\circ} \mathrm{C}$ compared to raw PA, due to 
the early decomposition of AP. The polyphosphoric acid released from the ammonium polyphosphate decomposition reacted with the amide bond to form intermediate phosphate ester bonds, leading to a decrease at $T_{50 \%}$ of $\mathrm{PA}$ by $40{ }^{\circ} \mathrm{C}$. A substantial thermal destabilization for the blend $\mathrm{PA}_{80}-\mathrm{AP}_{20}$ is also observed on the differential mass curve (Figure 4) between 350 and $500{ }^{\circ} \mathrm{C}$. The phosphate ester bonds decomposed at a higher temperature to promote the formation of char, it can be observed that the obtained residue at $600{ }^{\circ} \mathrm{C}$ is slightly higher than the theoretical values (Table 3).

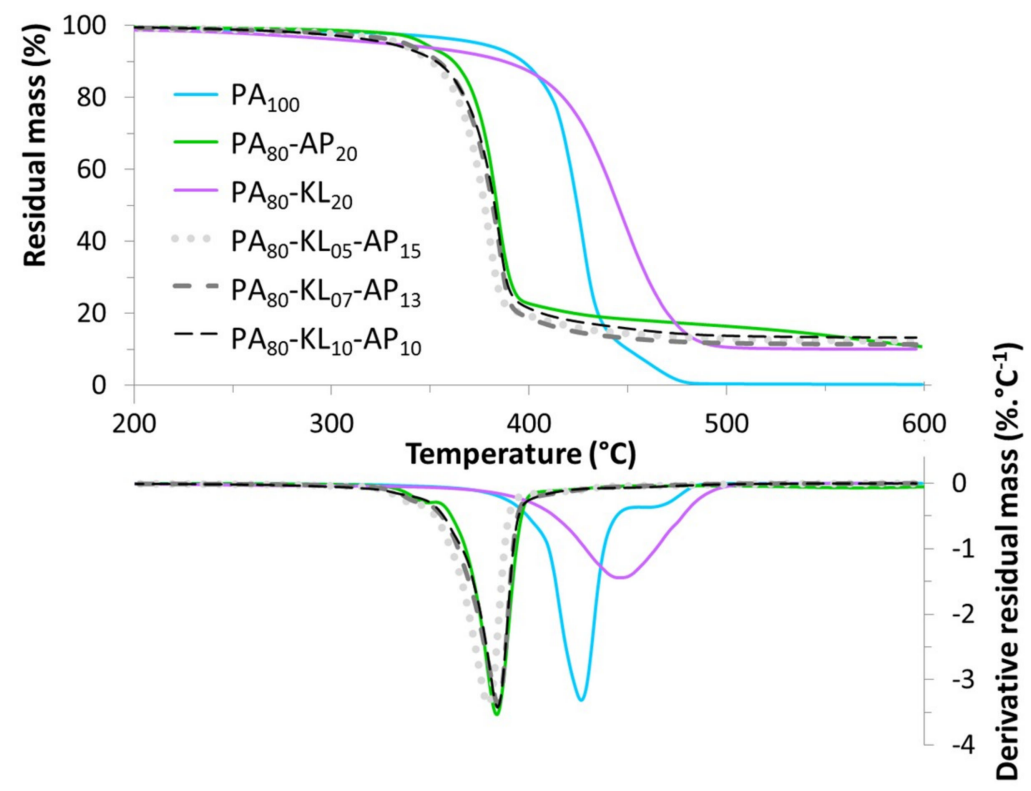

Figure 3. TG and DTG curves of PA and PA blends with AP and KL under nitrogen atmosphere.

Table 3. TGA results of PA and blends with lignin and/or ammonium polyphosphate under nitrogen atmosphere.

\begin{tabular}{|c|c|c|c|c|c|c|}
\hline \multirow{2}{*}{ Samples } & \multirow{2}{*}{$T_{5 \%}\left({ }^{\circ} \mathrm{C}\right)$} & \multirow{2}{*}{$T_{50 \%}\left({ }^{\circ} \mathrm{C}\right)$} & \multicolumn{3}{|c|}{$T_{\max }\left({ }^{\circ} \mathrm{C}\right) \& R_{\max }\left(\% \cdot{ }^{\circ} \mathrm{C}^{-1}\right)$} & \multirow{2}{*}{$\frac{\text { Residue }(\%)^{1}}{600{ }^{\circ} \mathrm{C}}$} \\
\hline & & & Step I & Step II & Step III & \\
\hline $\mathrm{PA}_{100}$ & 375 & 424 & $\begin{array}{c}426 \\
3.320\end{array}$ & $\begin{array}{c}463 \\
0.361\end{array}$ & - & 0.2 \\
\hline $\mathrm{PA}_{80}-\mathrm{AP}_{20}$ & 347 & 383 & $\begin{array}{c}384 \\
3.485\end{array}$ & - & - & $10.7(7.3)$ \\
\hline $\mathrm{PA}_{80}-\mathrm{KL}_{20}$ & 325 & 445 & $\begin{array}{c}445 \\
1.443\end{array}$ & - & - & $10.0(9.5)$ \\
\hline $\mathrm{PA}_{80}-\mathrm{KL}_{05}-\mathrm{AP}_{15}$ & 335 & 377 & $\begin{array}{c}379 \\
3.888\end{array}$ & - & - & $12.3(8.4)$ \\
\hline $\mathrm{PA}_{80}-\mathrm{KL}_{07}-\mathrm{AP}_{13}$ & 336 & 381 & $\begin{array}{c}384 \\
3.381\end{array}$ & - & - & $11.3(8.1)$ \\
\hline $\mathrm{PA}_{80}-\mathrm{KL}_{10}-\mathrm{AP}_{10}$ & 329 & 382 & $\begin{array}{c}384 \\
3.431\end{array}$ & - & - & $13.3(8.6)$ \\
\hline
\end{tabular}

${ }^{1}$ in brackets calculated values based on additive behavior.

The presence of lignin at $20 \%$ in PA is responsible for the decrease of $T_{5 \%}$ by $50{ }^{\circ} \mathrm{C}$, and an increase of $T_{50 \%}$ and $T_{\max }$ about $20^{\circ} \mathrm{C}$. Furthermore, the thermal degradation occurs in a single, broader stage. The decrease of $T_{5 \%}$ may be attributed to a rapid mass loss rate of KL at a lower temperature region. The difference between TG curves of raw and filled polymer (Figure 4) shows a noticeable thermal stabilization between 400 and $500{ }^{\circ} \mathrm{C}$. So KL permits a charring effect delaying thermal degradation of the blend in comparison with raw PA. However, above $500{ }^{\circ} \mathrm{C}$ the residual mass difference of 
the blend is 0 and the residue amounts correspond to the KL content after its degradation. Thus, it can be concluded that there is no interaction between decomposition products of PA and KL.

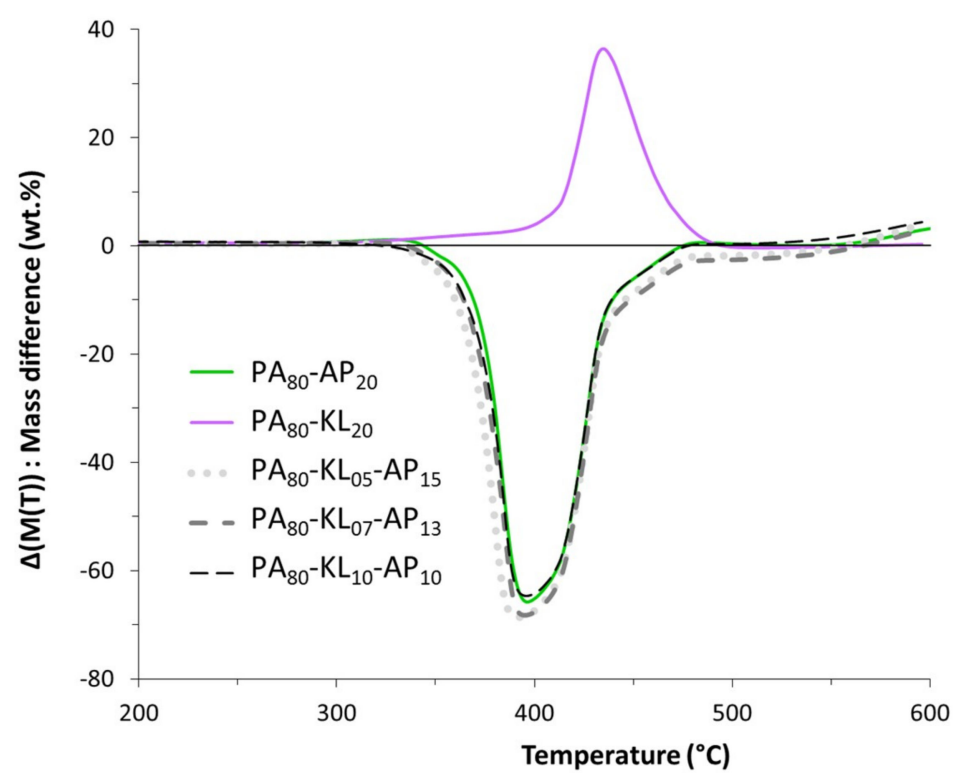

Figure 4. Curves of residual mass loss difference for PA blends with AP and KL.

The mass loss behavior of $\mathrm{PA}_{80}-\mathrm{KL}_{05}-\mathrm{AP}_{15}, \mathrm{PA}_{80}-\mathrm{KL}_{07}-\mathrm{AP}_{13}$, and $\mathrm{PA}_{80}-\mathrm{KL}_{10}-\mathrm{AP}_{10}$ samples (Figure 3) are almost similar, and their DTG maxima are observed at 379 and $384{ }^{\circ} \mathrm{C}$, respectively. The influence of AP in the thermal degradation of the ternary blends is predominant since their TG curve is closed to the TG curve of $\mathrm{PA}_{80}-\mathrm{AP}_{20}$. The onset temperature, $T_{5 \%}$, of the ternary blends are found to be decreased compared to raw PA and also PA-AP samples, by 40 to $50{ }^{\circ} \mathrm{C}$ and 11 to $18{ }^{\circ} \mathrm{C}$, respectively. Their decomposition temperatures $\left(T_{\max }\right)$ are decreased compared to that of raw $\mathrm{PA}$, whereas the maximum rates of degradation are found to be slightly increased for the samples $\mathrm{PA}_{80}-\mathrm{KL}_{07}-\mathrm{AP}_{13}$ and $\mathrm{PA}_{80}-\mathrm{KL}_{10}-\mathrm{AP}_{10}$, and more significantly for the $\mathrm{PA}_{80}-\mathrm{KL}_{05}-\mathrm{AP}_{15}$ one. Therefore, the presence of AP has a catalyzing effect on the degradation of PA, which is stronger in presence of KL in the initial step of degradation. Furthermore, the TG curve of KL shows that $7 \%$ of $\mathrm{KL}$ decomposes at $220^{\circ} \mathrm{C}$, i.e., at processing temperature to prepare PA-KL-AP blends. Thus, the decrease of $T_{5 \%}$ of these blends by 30 to $40{ }^{\circ} \mathrm{C}$ is due to early decomposition of $\mathrm{KL}$ and AP. As for mass loss difference of $\mathrm{PA}_{80}-\mathrm{AP}_{20}$ sample, the mass loss difference of the three ternary blends (Figure 4) presents a critical thermal destabilization period from 350 and $500{ }^{\circ} \mathrm{C}$. It can also be noticed that the thermal degradation of the three ternary blends seems to be irrelevant of the AP to KL weight ratio used in this study, since the change trends of TG curves between all samples are similar, even if there are still some differences. The initial decomposition temperature of $\mathrm{PA}_{80}-\mathrm{KL}_{10}-\mathrm{AP}_{10}$ is lower than the two other samples ones. Besides, for a sufficient AP content, when samples begin to degrade, the charring aromatic radicals coming from KL reduce the polymer degradation rate increasing the composite thermal degradation temperature by $5{ }^{\circ} \mathrm{C}$. On the other hand, the residue left at $600{ }^{\circ} \mathrm{C}$ for $\mathrm{PA}_{80}-\mathrm{KL}_{05}-\mathrm{AP}_{15}, \mathrm{PA}_{80}-\mathrm{KL}_{07}-\mathrm{AP}_{13}$, and $\mathrm{PA}_{80}-\mathrm{KL}_{10}-\mathrm{AP}_{10}$ are about $12.3,11.3$, and 13.3, respectively, suggesting higher charring than PA-KL and PA-AP samples. Therefore, the increase in the amount of residue may be owing to the formation of more stable carbonaceous char. Indeed, the char yield for the three ternary blends at $600^{\circ} \mathrm{C}$ (Table 3) is higher than the sum of the individual contributions of each component. Thus, more effective carbonizing and cross-linking reactions take place during the PA degradation on the addition of AP with KL in comparison to KL or AP solely. From the above results, It seems that the blend with the 50:50 weight ratio of KL and AP is better than the two other ones (25:75 and 33:67) in improving the charring of the PA composite. 


\subsection{Flammability Behavior}

The results of the UL94 tests for PA and the blends are summarized in Table 4, and the typical pictures of the specimens left after the tests are shown in Figure 5.

Table 4. UL94 vertical flame spread test data for PA and its blends.

\begin{tabular}{ccccccc}
\hline Samples & $\begin{array}{c}\text { 1st Flame } \\
\mathbf{t}_{\mathbf{1}} \mathbf{( s )}\end{array}$ & $\begin{array}{c}\mathbf{2 n d} \text { Flame } \\
\mathbf{t}_{\mathbf{2}} \mathbf{( \mathbf { s } )}\end{array}$ & $\begin{array}{c}\text { Combustion } \\
\text { Time } \mathbf{( t}_{\mathbf{1}}+\mathbf{t}_{\mathbf{2}} \mathbf{)}\end{array}$ & Cotton Ignition & Rating & $\begin{array}{c}\text { Mass Loss } \\
\mathbf{( \% )}\end{array}$ \\
\hline $\mathrm{PA}_{100}$ & $1.6 \pm 0.4$ & $2.4 \pm 0.6$ & $4.0 \pm 1.0$ & Yes & $\mathrm{V} 2$ & $33.7 \pm 10.9$ \\
$\mathrm{PA}_{80}-\mathrm{AP}_{20}$ & $8.9 \pm 5.9$ & $4.8 \pm 1.6$ & $13.7 \pm 5.7$ & Yes & $\mathrm{V} 2$ & $34.7 \pm 4.9$ \\
$\mathrm{PA}_{80}-\mathrm{KL}_{20}$ & $1.1 \pm 0.1$ & $14.4 \pm 11.3$ & $15.5 \pm 11.5$ & Yes & $\mathrm{V} 2$ & $64.1 \pm 3.3$ \\
$\mathrm{PA}_{80}-\mathrm{KL}_{05}-\mathrm{AP}_{15}$ & $1.9 \pm 0.9$ & $2.7 \pm 1.4$ & $4.6 \pm 1.9$ & Yes & $\mathrm{V} 2$ & $21.4 \pm 3.3$ \\
$\mathrm{PA}_{80}-\mathrm{KL}_{07}-\mathrm{AP}_{13}$ & $3.0 \pm 2.2$ & $7.0 \pm 1.9$ & $10.0 \pm 1.2$ & Yes & $\mathrm{V} 2$ & $19.1 \pm 4.5$ \\
$\mathrm{PA}_{80}-\mathrm{KL}_{10}-\mathrm{AP}_{10}$ & $6.6 \pm 0.7$ & $22.8 \pm 5.9$ & $29.4 \pm 6.5$ & Yes & $\mathrm{V} 2$ & $81.5 \pm 16.6$ \\
\hline
\end{tabular}

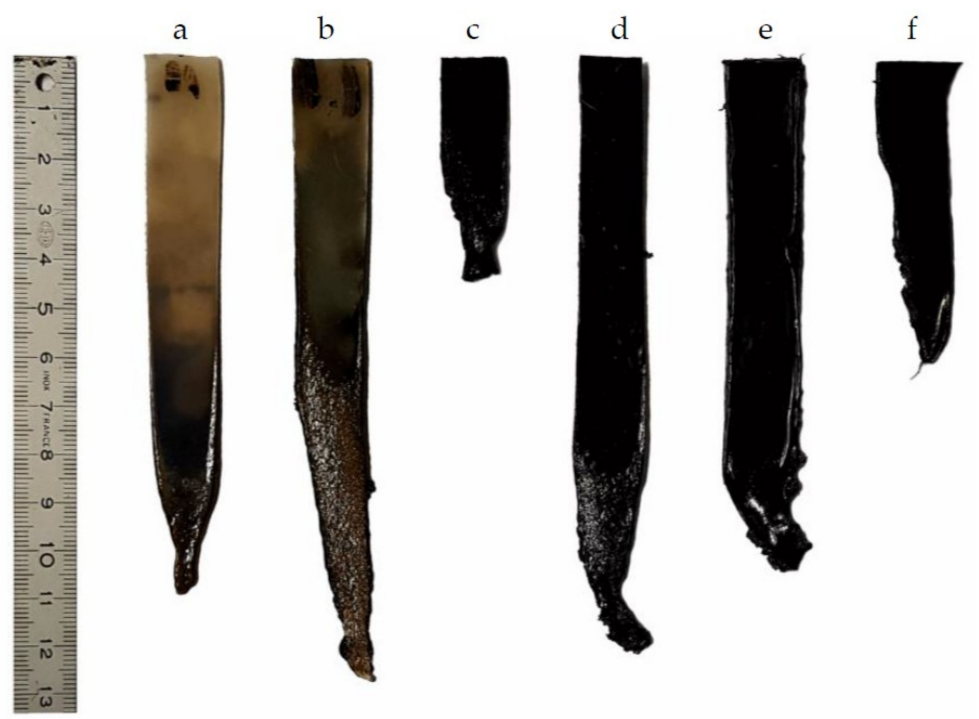

Figure 5. Pictures of PA blends specimen left after UL 94 vertical flame test. (a) PA; (b) $\mathrm{PA}_{80}-\mathrm{AP}_{20}$; (c) $\mathrm{PA}_{80}-\mathrm{KL}_{20}$; (d) $\mathrm{PA}_{80}-\mathrm{KL}_{05}-\mathrm{AP}_{15}$; (e) $\mathrm{PA}_{80}-\mathrm{KL}_{07}-\mathrm{AP} 13$; (f) $\mathrm{PA}_{80}-\mathrm{KL}_{10}-\mathrm{AP}_{10}$.

Dripping and cotton ignition were observed in all the blends. Just after the flame exposure, PA presents a significant dripping of burning materials. As already described in literature for some thermoplastic polymers like Polyamide 6 [28], the dripping is so consequent that the flame spread is limited and so the remaining preserved material is noticeable. The presence of AP or/and KL does not give significant improvement in the burning behavior of PA. With $20 \%$ of $\mathrm{AP}$, we can observe during flame exposition a low charring effect with some crackling due to gas action of AP (ammonia and water release). Contrary to raw $\mathrm{PA}$, the combustion is maintained during $10 \mathrm{~s}$ more in total after removing of the flame. The flame behavior of thermoplastic polymers in the vertical direction is complex, not only the mechanisms of thermal degradation have a determining role, but the viscoelastic properties in the molten state are also crucial [29]. The viscosity of molten $\mathrm{PA}_{80}-\mathrm{AP}_{20}$ blend is higher than for PA (Table S1). This difference of viscosity could be not favorable to $\mathrm{PA}_{80}-\mathrm{AP}_{20}$ blend from a flame spread point of view. The combustion stopped finally by dripping of burning materials. The combustion time for $\mathrm{PA}_{80}-\mathrm{KL}_{20}$ after the first flame exposure is short due to a rapid dripping of burning material, but after the $2^{\text {nd }}$ exposure, the dripping is slowed down, and a small flame spread during almost $15 \mathrm{~s}$ destroyed two-thirds of the samples. The best results are obtained with $\mathrm{PA}_{80}-\mathrm{KL}_{05}-\mathrm{AP}_{15}$ and $\mathrm{PA}_{80}-\mathrm{KL}_{07}-\mathrm{AP}_{13}$ which show a significant flame behavior improvement. A charring effect with some intumescence is observable during flame exposure, and the material is self-extinguishing after the first exposure. During the second exposure, some burning material drips but the samples kept finally about $80 \%$ 
of the initial mass. In the case of $\mathrm{PA}_{80}-\mathrm{KL}_{10}-\mathrm{AP}_{10}$, the charring effect is lower than in the case of the two other ternary blends, and no intumescence is observed, allowing the flame to spread on almost the entire sample.

\subsection{Combustion Behavior}

The PCFC experiments provide access to the heat release rate from the complete combustion of fuel released during the anaerobic pyrolysis of the material. Table 5 presents for each PA blend the peak of heat release rate with its temperature, the total heat release, the char residue, and the heat of complete combustion. The Figure 6 shows the curves of HRR. HRR curves are in good agreement with DTG curves in Figure 3. Indeed, pyrolysis conditions are similar in PCFC and TGA in nitrogen.

Table 5. Pyrolysis combustion flow calorimetry (PCFC) data for PA and its blends. pHRR: peak of heat release rate; THR: total heat release; $\Delta \mathrm{h}$ : heat of complete combustion.

\begin{tabular}{cccccccc}
\hline Samples & $\begin{array}{c}\text { pHRR } \\
(\mathbf{W} / \mathbf{g})\end{array}$ & $\begin{array}{c}\text { pHRR } \\
\text { Reduction } \\
\mathbf{( \% )}\end{array}$ & $\begin{array}{c}\text { pHRR } \\
\text { Temperature } \\
\left({ }^{\circ} \mathbf{C}\right)\end{array}$ & $\begin{array}{c}\text { THR } \\
\mathbf{( K J / g )}\end{array}$ & $\begin{array}{c}\text { THR } \\
\text { Reduction } \\
(\mathbf{\%})\end{array}$ & $\begin{array}{c}\text { Residue } \\
\mathbf{( \% )}\end{array}$ & $\begin{array}{c}\Delta \mathbf{h} \\
(\mathbf{K J} / \mathbf{g})\end{array}$ \\
\hline $\mathrm{PA}_{100}$ & $1293 \pm 39$ & - & $413 \pm 2$ & $32.4 \pm 0.1$ & - & $3.2 \pm 0.3$ & $33.6 \pm 0.4$ \\
$\mathrm{PA}_{80}-\mathrm{AP}_{20}$ & $1108 \pm 92$ & 14 & $382 \pm 3$ & $29.3 \pm 0.4$ & 10 & $11.4 \pm 0.0$ & $33.0 \pm 0.4$ \\
$\mathrm{PA}_{80}-\mathrm{KL}_{20}$ & $442 \pm 5$ & 66 & $451 \pm 2$ & $28.3 \pm 0.1$ & 13 & $11.0 \pm 0.2$ & $31.7 \pm 0.1$ \\
$\mathrm{PA}_{80}-\mathrm{KL}_{05}-\mathrm{AP}_{15}$ & $993 \pm 30$ & 23 & $380 \pm 1$ & $27.9 \pm 0.2$ & 14 & $14.4 \pm 0.4$ & $32.6 \pm 0.4$ \\
$\mathrm{PA}_{80}-\mathrm{KL}_{07}-\mathrm{AP}_{13}$ & $908 \pm 47$ & 30 & $379 \pm 0$ & $26.8 \pm 0.5$ & 17 & $13.9 \pm 0.1$ & $31.1 \pm 0.6$ \\
$\mathrm{PA}_{80}-\mathrm{KL}_{10}-\mathrm{AP}_{10}$ & $924 \pm 19$ & 29 & $383 \pm 2$ & $26.9 \pm 0.9$ & 17 & $12.1 \pm 0.3$ & $30.5 \pm 0.4$ \\
\hline
\end{tabular}

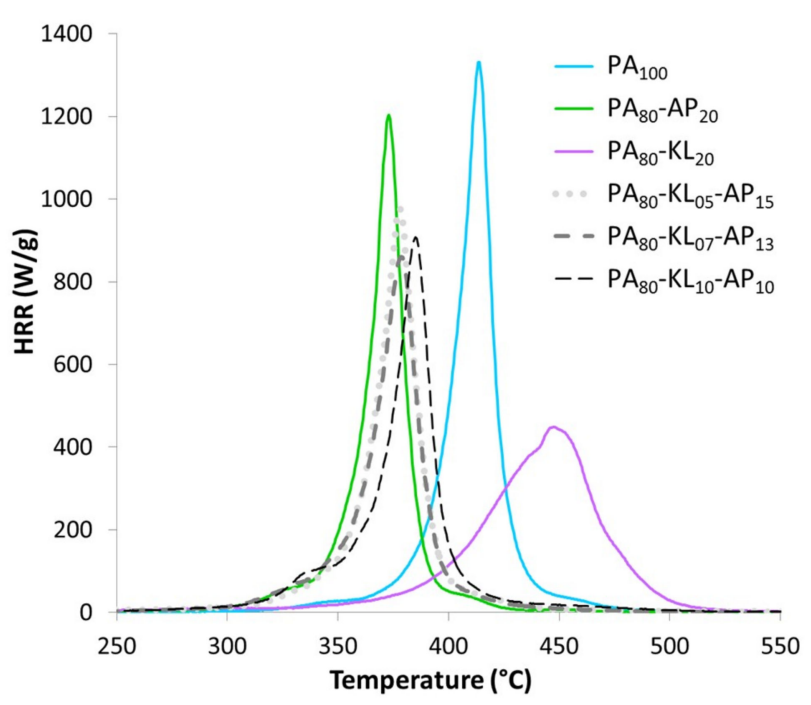

Figure 6. Curves of heat release rate (HRR) from PCFC experiments for PA blends with AP and KL.

Among the PA blends with $\mathrm{KL}$ and/or $\mathrm{AP}$, the $\mathrm{PA}_{80}-\mathrm{KL}_{20}$ blend presents the best behavior combustion since the pHRR is decreased by $66 \%$ and shifted by around $+40{ }^{\circ} \mathrm{C}$ in comparison of raw PA. The PCFC results for $\mathrm{PA}_{80}-\mathrm{KL}_{20}$ blend are correlated to the fact that the thermal degradation with $20 \%$ of KL is delayed, and slowed down compared to raw PA. However, the residue content for the $\mathrm{PA}_{80}-\mathrm{KL}_{20}$ blend remains quite low, and so the total heat released of $\mathrm{PA}_{80}-\mathrm{KL}_{20}$ is only slightly decreased $(13 \%)$ compared to the THR of raw PA. The decrease of the $\Delta \mathrm{h}$ for $\mathrm{PA}_{80}-\mathrm{KL}_{20}$ blend $(31.7 \mathrm{~kJ} / \mathrm{g})$ is limited ( $33.6 \mathrm{~kJ} / \mathrm{g}$ for raw PA) and can be assigned to the replacement of a fraction of PA by KL having a low heat of combustion (around $10 \mathrm{~kJ} / \mathrm{g}$ ) [30]. Given PCFC results, the $\mathrm{PA}_{80}-\mathrm{AP}_{20}$ shows the lowest improvement of flame retardant effect. The HRR peak, the THR and the $\triangle \mathrm{h}$ of $\mathrm{PA}_{80}-\mathrm{AP}_{20}$ are closed to the raw PA values. Moreover, since $\mathrm{PA}_{80}-\mathrm{AP}_{20}$ has lower thermal stability than PA, the $\mathrm{pHRR}$ for $\mathrm{PA}_{80}-\mathrm{AP}_{20}$ is $30{ }^{\circ} \mathrm{C}$ below. The PCFC results for the three ternary blends are slightly better than for $\mathrm{PA}_{80}-\mathrm{AP}_{20}$ blend. Once again, residue content is slightly enhanced compared to binary 
blends. Therefore THR is reduced. Nevertheless, the destabilization due to AP leads to a pHRR at low temperature (around $30^{\circ} \mathrm{C}$ below than that of PA, and the pHRR remains very high even if it is slightly reduced compared to raw $\mathrm{PA}$ and $\mathrm{PA}_{80}-\mathrm{AP}_{20}$.

\section{Conclusions}

The thermogravimetric analyses of the kraft lignin/ammonium polyphosphate powder mixtures, respectively charring agent and acidic source for potential flame retardant intumescent formulation point out noticeable interactions between both components whatever the ratio of the mixture. However, the KL-AP ratio influences these interactions. The curves of residual mass loss difference for KL-AP powder blends reveal a positive interaction between around 300 and $500{ }^{\circ} \mathrm{C}$. However, unlike the $\mathrm{KL}_{25}-\mathrm{AP}_{75}$ and $\mathrm{KL}_{33}-\mathrm{AP}_{67}$ mixtures, only the $\mathrm{KL}_{50}-\mathrm{AP}_{50}$ mixture which has the highest residue at $800^{\circ} \mathrm{C}$ keeps a positive interaction above $600{ }^{\circ} \mathrm{C}$. The influence of KL-AP ratio on the thermal decomposition of the PA-KL-AP blends is low. The thermal degradations of the different ternary blends are similar and close to the decomposition of the PA-AP blend. AP finally dominates the degradation of the ternary blends. On the other hand, the presence of $20 \%$ of KL alone in PA has a positive effect on the thermal degradation with a delay in the main PA degradation step. The analyze of the fire behavior for the different PA blends by PCFC indicates that the fire retardant capacity of the ternary blends is intermediate considering the peak of HRR between these of the PA-AP and PA-KL blends. If the PA-KL blend shows the smallest peak of HRR, it is probably due mainly to the low combustion heat of the lignin. The KL-PA blend also presents the worst result with UL94 flammability test and, contrary to the PCFC test where the fire retardant effect by intumescence are not favored, the ternary blends present the best results even if they still V2 ranking due to creep phenomenon. For this test, the KL-AP ratio seems to have of influence since the formation of an efficiently expanded char is observed only for the $\mathrm{PA}_{80}-\mathrm{KL}_{05}-\mathrm{AP}_{15}$ and $\mathrm{PA}_{80}-\mathrm{KL}_{07}-\mathrm{AP}_{13}$ blends. In the case of $\mathrm{PA}_{80}-\mathrm{KL}_{10}-\mathrm{AP}_{10}$ blend, the flame behavior becomes more similar to the $\mathrm{PA}_{80}-\mathrm{KL}_{20}$ blend. Even if interactions between $\mathrm{AP}$ and KL exist, once both components are dispersed in PA, these interactions develop less. That is why the ternary blends do not present synergy on fire retardant aspect. Nevertheless, the ratio KL-AP affects the PA fire behavior, and given all the results, the $\mathrm{PA}_{80}-\mathrm{KL}_{07}-\mathrm{AP}_{13}$ blend seems to have the best fire retardant.

Supplementary Materials: The following are available online at http:/ /www.mdpi.com/1996-1944/12/7/1146/ s1, Table S1: Melting Flow Index for PA and its blends.

Author Contributions: Conceptualization, A.C., F.R., S.G. and F.S.; methodology, A.C., F.R., S.G. and F.S.; software, A.C., F.R., S.G. and F.S.; validation, A.C., F.R., S.G. and F.S.; formal analysis, A.C., F.R., S.G., F.S., R.S. and L.D.; investigation, A.C., F.R., S.G. and F.S.; resources, A.C., F.R., S.G., F.S., R.S. and L.D.; data curation, A.C., F.R., S.G. and F.S.; writing-original draft preparation, A.C., F.R., S.G. and F.S.; writing—review and editing, A.C., F.R., S.G., F.S., and R.S.; visualization, A.C., F.R., S.G. and F.S.; supervision, S.G. and F.S.; project administration, S.G. and F.S.; funding acquisition, A.C., F.R., S.G. and F.S.

Funding: This research received no external funding.

Acknowledgments: The authors gratefully acknowledge Guillaume Lemort (ENSAIT, GEMTEX) for technical support (UL 94 burning flame test).

Conflicts of Interest: The authors declare no conflict of interest.

\section{References}

1. Hobbs, C.E. Recent advances in bio-based flame retardant additives for synthetic polymeric materials. Polymers 2019, 11, 224. [CrossRef]

2. Réti, C.; Casetta, M.; Duquesne, S.; Bourbigot, S.; Delobel, R. Flammability properties of intumescent PLA including starch and lignin. Polym. Adv. Technol. 2008, 19, 628-635. [CrossRef]

3. Wang, X.; Hu, Y.; Song, L.; Xuan, S.; Xing, W.; Bai, Z.; Lu, H. Flame retardancy and thermal degradation of intumescent flame retardant poly(lactic acid)/starch Biocomposites. Ind. Eng. Chem. Res. 2011, 50, 713-720. [CrossRef] 
4. Maqsood, M.; Seide, G. Investigation of the flammability and thermal stability of halogen-free intumescent system in biopolymer composites containing biobased carbonization agent and mechanism of their char formation. Polymers 2018, 11, 48. [CrossRef]

5. Feng, J.-X.; Su, S.-P.; Zhu, J. An intumescent flame retardant system using $\beta$-cyclodextrin as a carbon source in polylactic acid (PLA). Polym. Adv. Technol. 2011, 22, 1115-1122. [CrossRef]

6. Wang, X.; Xing, W.; Wang, B.; Wen, P.; Song, L.; Hu, Y.; Zhang, P. Comparative Study on the Effect of Beta-Cyclodextrin and Polypseudorotaxane As Carbon Sources on the Thermal Stability and Flame Retardance of Polylactic Acid. Ind. Eng. Chem. Res. 2013, 52, 3287-3294. [CrossRef]

7. Vahabi, H.; Shabanian, M.; Aryanasab, F.; Laoutid, F.; Benali, S.; Saeb, M.R.; Seidi, F.; Kandola, B.K. Three in one: $\beta$-cyclodextrin, nanohydroxyapatite, and a nitrogen-rich polymer integrated into a new flame retardant for poly (lactic acid). Fire Mater. 2018, 42, 593-602. [CrossRef]

8. Chen, C.; Gu, X.; Jin, X.; Sun, J.; Zhang, S. The effect of chitosan on the flammability and thermal stability of polylactic acid/ammonium polyphosphate biocomposites. Carbohydr. Polym. 2017, 157, 1586-1593. [CrossRef]

9. Costes, L.; Laoutid, F.; Brohez, S.; Dubois, P. Bio-based flame retardants: When nature meets fire protection. Mater. Sci. Eng. R Reports 2017, 117, 1-25. [CrossRef]

10. Ferry, L.; Dorez, G.; Taguet, A.; Otazaghine, B.; Lopez-Cuesta, J.M. Chemical modification of lignin by phosphorus molecules to improve the fire behavior of polybutylene succinate. Polym. Degrad. Stab. 2015, 113, 135-143. [CrossRef]

11. Wu, W.; He, H.; Liu, T.; Wei, R.; Cao, X.; Sun, Q.; Venkatesh, S.; Yuen, R.K.K.; Roy, V.A.L.; Li, R.K.Y. Synergetic enhancement on flame retardancy by melamine phosphate modified lignin in rice husk ash filled P34HB biocomposites. Compos. Sci. Technol. 2018, 168, 246-254. [CrossRef]

12. Zhang, R.; Xiao, X.; Tai, Q.; Huang, H.; Hu, Y. Modification of lignin and its application as char agent in intumescent flame-retardant poly(lactic acid). Polym. Eng. Sci. 2012, 52, 2620-2626. [CrossRef]

13. Zhang, R.; Xiao, X.; Tai, Q.; Huang, H.; Yang, J.; Hu, Y. Preparation of lignin-silica hybrids and its application in intumescent flame-retardant poly(lactic acid) system. High Perform. Polym. 2012, 24, 738-746. [CrossRef]

14. Zhang, R.; Xiao, X.; Tai, Q.; Huang, H.; Yang, J.; Hu, Y. The effect of different organic modified montmorillonites (OMMTs) on the thermal properties and flammability of PLA/MCAPP/lignin systems. J. Appl. Polym. Sci. 2013, 127, 4967-4973. [CrossRef]

15. Cayla, A.; Rault, F.; Giraud, S.; Salaün, F.; Fierro, V.; Celzard, A. PLA with intumescent system containing lignin and ammonium polyphosphate for flame retardant textile. Polymers 2016, 8, 331. [CrossRef]

16. Costes, L.; Laoutid, F.; Brohez, S.; Delvosalle, C.; Dubois, P. Phytic acid-lignin combination: A simple and efficient route for enhancing thermal and flame retardant properties of polylactide. Eur. Polym. J. 2017, 94, 270-285. [CrossRef]

17. Song, Y.; Zong, X.; Wang, N.; Yan, N.; Shan, X.; Li, J. Preparation of $\gamma$-Divinyl-3-Aminopropyltriethoxysilane modified lignin and its application in flame retardant poly(lactic acid). Materials 2018, 11, 1505. [CrossRef]

18. Mandlekar, N.; Cayla, A.; Rault, F.; Giraud, S.; Salaün, F.; Malucelli, G.; Guan, J. Thermal stability and fire retardant properties of Polyamide 11 microcomposites containing different lignins. Ind. Eng. Chem. Res. 2017, 56. [CrossRef]

19. Mandlekar, N.; Malucelli, G.; Cayla, A.; Rault, F.; Giraud, S.; Salaün, F.; Guan, J. Fire retardant action of zinc phosphinate and polyamide 11 blend containing lignin as a carbon source. Polym. Degrad. Stab. 2018, 153, 63-74. [CrossRef]

20. Mandlekar, N.; Cayla, A.; Rault, F.; Giraud, S.; Salaün, F.; Guan, J. Valorization of industrial lignin as biobased carbon source in fire retardant system for Polyamide 11 blends. Polymers 2019, 11, 180. [CrossRef]

21. Levchik, S.V.; Costa, L.; Camino, G. Effect of the fire-retardant, ammonium polyphosphate, on the thermal decomposition of aliphatic polyamides. I. Polyamides 11 and 12. Polym. Degrad. Stab. 1992, 36, 31-41. [CrossRef]

22. Troitzsch, J. Plastics Flammability Handbook: Principles, Regulations, Testing, and Approval, 3rd ed.; Carl Hanser Verlag: Munich, Germany, 2004; pp. 514-516.

23. Lyon, R.E.; Walters, R.N. Pyrolysis combustion flow calorimetry. J. Anal. Appl. Pyrolysis 2004, 71, 27-46. [CrossRef]

24. Brebu, M.; Vasile, C. Thermal Degradation of Lignin-A review. Cellul. Chem. Technol. 2010, 44, $353-363$. 
25. Rodrigues, J.; Graça, J.; Pereira, H. Influence of tree eccentric growth on syringyl/guaiacyl ratio in Eucalyptus globulus wood lignin assessed by analytical pyrolysis. J. Anal. Appl. Pyrolysis 2001, 58-59, 481-489. [CrossRef]

26. Wittkowski, R.; Ruther, J.; Drinda, H.; Rafiei-Taghanaki, F. Formation of smoke flavor compounds by thermal lignin degradation. In Proceedings of the ACS Symposium Series; American Chemical Society (ACS): Washington, DC, USA, 1992; Volume 490, pp. 232-243.

27. Kandola, B.K.; Horrocks, A.R. Complex char formation in flame-retarded fibre-intumescent combinations-II. Thermal analytical studies. Polym. Degrad. Stab. 1996, 54, 289-303. [CrossRef]

28. Wang, Y.; Zhang, F.; Chen, X.; Jin, Y.; Zhang, J. Burning and dripping behaviors of polymers under the UL94 verticla burning test conditions. Fire Mater. 2010, 34, 203-215. [CrossRef]

29. 29 Joseph, P.; Tretsiakova-McNally, S. Melt-flow behaviours of thermoplastic materials under fire conditions: Recent experimental studies and some theoretical approaches. Materials 2015, 8, 8793-8803. [CrossRef]

30. Dorez, G.; Ferry, L.; Sonnier, R.; Taguet, A.; Lopez-Cuesta, J.-M. Effect of cellulose, hemicellulose and lignin contents on pyrolysis and combustion of natural fibers. J. Anal. Appl. Pyrolysis 2014, 107, 323-331. [CrossRef]

(C) 2019 by the authors. Licensee MDPI, Basel, Switzerland. This article is an open access article distributed under the terms and conditions of the Creative Commons Attribution (CC BY) license (http://creativecommons.org/licenses/by/4.0/). 